figures are also given in the standard works of Westwood and Packard on insects. As W. E. L. is probably a practical man, he will do well to consider the proofs afforded by Mr. Elliot that the "ked," as they call it in Scotland, is anything but the harmless insect which some people imagine it to be.

T. Spencer Cobbold

I AM inclined to think your correspondent W. E. L., on the subject of "ticks" (p. 53I), may have confounded two quite distinct animal forms under that name. The sheep-tick or louse, as shepherds call it, found at the roots of the wool on sheep, and which $I l$ ave often formerly had brought to me under one of those names, is an aberrant form of Hippobosca, a genus of dipterous insects, the typical species being the well-known forestfly. An excellent figure of the sheep tick will be found in Curtis's "British Entomology," P1. 142, under the name of Melophagus ovinus.

Ixodes is a genus of the Acaridæ, a group easily distinguished from the true insects by their having eight legs in the adult state. Six British species of Ixodes are described by Dr. Leach in vol. xi. of the Linnean Transaitions. There are probably others not as yet determined. The one best known is the common dog-tick, found in a free state in woods and plantations, and attaching itself not merely to dogs but to hares, \&c., and especially to hedgehogs, which often abound with them, the ticks getting their hold as the animals pass through the close grass. After attachment they soon get gorged with blood, their abdomens swelling to an immense size comp ared with the insignificant appearance of them previous to attachment. But I can remember no instance of an Ixodes found on a sheep, though I would not undertake to say they never occur on that animal.

Bath

L. BLOMEFIELD

\section{Helix pomatia, L.}

I AGREe with Mr. Gwyn Jeffreys (NATURE, p. 5II) in considering Helix pomatia as indigenous in this country, and not introduced by the Romans. I never found or heard of a single specimen, either living or dead shell, being met with in the neighbourhood of Bath, which the Romans occupied for more than 400 years, though it is found in one or two localities in the adjoining county of Gloucestershire, from whence we have specimens in the museum of the Bath Literary Institution.

Bath

L. BLOMEFIELD

\section{Braces or Waistband?}

HAVING worn a Spanish sash for some tirne many years ago while walking in the Pyrenees, I am decidedly of opinion that the weight of the trousers is supported much more easily and pleasantly by a sash than by braces; these last are narrow, about 2 inches wide, and though custom enables us to wear them w ithout conscious inconvenience, I think any one using them for the first time would find them very unpleasant. The sash worn by the middle and lower class in Aragon is of wool 8 or 9 inches broad, and (if my recollection is correct) about $4 \frac{1}{2}$ feet long; when of such width and length it cioes not need to be drawn iight, but only closely wrapped round the waist and the end tucked in. I should certainly wear one constantly but that I do not wish to have an eccentric appearance. Medical men, I believe, attach great value to the wearing of sashes or bands round the stomach, especially in hot countries. A narrow silken sash which must be drawn tight is, I should suppose, far less pleasant to wear.

N.

SOLAR RADIATION AND GLACIER MOTION

I $N$ the paper on the "Mechanics of Glaciers," which 1 the author had the honour to read before the Geological Society of London in December last, it is stated that, after all allowance is made for work within the glacier due to the potential energy of the weight of the ice-mass, "there remains to be accounted for a secondary differential motion, which has, it appears, not yet received a satisfactory explanation ... the movement is greater $(a)$ by day than by night, $(b)$ in summer than in winter." The present paper is intended as nothing more than a brief statement of the experimental evidence, upon the strength of which the explanation offered in the paper referred to has been put forward. I may say en passant that this investigation was suggested to me by a statement of Dr. Croll's ("Climate and Time," p. 519) that, "We find that the heat applied to one side of a piece of ice will affect the thermal pile on the opposite side." It occurred to me that the looseness of this statement was quite in keeping with the unphysical notions upon which the writer has built up what he styles his "molecular theory" of glacier motion, and I set to work therefore to investigate its accuracy.

The principal apparatus used consisted of a delicate galvanometer, and a thermopile of a pretty high degree of sensitiveness, made up as it is of eighty-one couples of bismuth and antimony; the measurements were read off numerically by the light reflected on the scale as usual. Suspecting that the fallacy of the statement referred to lay in overlooking the effect of luminous energy, which of course is capable of passing through any transparent body, I made a few preliminary trials with glass and water, not having ice then at hand. A beam of solar radiation, having passed through two inches of distilled cold water + half an inch of glass, was allowed to fall upon a Crookes' radiometer ; this made the vanes rotate too fast for their rotations to be counted, even when the instrument was enclosed in a wooden case on all sides exceft that open to the glass-water screen through which the sunshine passed. A beam of solar light, having been sifted of its dark heat-rays in the same manner as before, was received upon the absorbing face of the thermopile, producing a considerable deflection of the magnet in the galvanometer, even with the feeble sunshine of our recent December days.

The next step was a series of trials with ice itself. In the first instance, trials were made with the plates of ice in contact with the metallic face of the pile, the black (absorbing) face being placed at a distance of 3 inches opposite a large Bunsen flame in a room free froms trong draughts : in this way a constant difference of $36^{\circ} \mathrm{C}$. was obtained for the opposite faces of the pile, and maintained for more than half an hour, with the needle of the galvanometer quite stationary. An iron ball 3 inches in diameter, having been heated to dull redness (clearly perceptible in a dark room), was placed opposite the plate of ice ( $\mathrm{I}$ inch thick) in contact with the pile, and allowed to cool. It was again heated as before, and placed at a distance of less than an inch from the ice (now less than half an inch thick), and allowed to cool. In both cases the effect observed upon the galvanometer was absolute nil, even when, in the second trial, the ice had become so thin by melting as to break under the small force required to hold it against the pile.

In the next series of trials the arrangement was reversed, the ice being placed just in front of the condensing cone attached to the absorbing face of the pile at a distance of 4 inches; the metallic face of the instrument was maintained at a constant temperature by contact with a vessel of cold water, whose temperature was observed frequently, and found to be practically constant. On the distant side of the ice was placed a double boardscreen, with air-space and a circular hole to allow the passage of a cylindrical beam of radiation of the same diameter as the condensing cone. The iron ball, heated to dull red heat as before, was placed opposite the hole of the screen, at a distance of $7 \frac{1}{2}$ inches from the face of the pile, the intervening ice-plate in this case being $I$ inch thick, and the galvanometer having been stationary for half-an-hour before the experiment was made. Under the same conditions the experiment was repeated (I) with $\frac{1}{4}$-inch plate of ice; (2) with $\frac{1}{4}$-inch of pond-ice + wet half-melted snow ; (3) with 5 -inch of fresh-fallen snow. In all these cases the result of the obscure radiation from the ball upon the galvanometer was absolute nil, although, without the interposition of ice or snow, the maximum 
deflection at the end of 5 minutes was $460^{\circ}$ on the scale (see accompanying table). This period of time was adopted for this reason, for the duration of each following experiment, though more than needed to produce maximum results. So far the evidence is conclusive that dark heat (i.e. heat capable of melting ice) applied to one side of a piece of ice does not affect the thermopile on the opposite side. So much for the negative results.

It seemed to me at this point worth while to investigate the effects produced by luminous radiant energy of various phases of quality after transmission through ice, which, it would appear, effectually barred the passage of all the obscure rays of the iron ball from even entering it, while the liquefaction of the ice at the surface was beyond all comparison greater than that which goes on at the surface of a glacier even with a full midsummer sun. The sources of luminous energy chosen are given in the first column of the following table. The feeble effect produced by the blue flame of a very large Bunsen lamp (giving no red, orange, or yellow when examined with the spectroscope) as compared with the effects produced by the more highly luminous gas-flames of far inferior thermal intensity (which gave, of course, a complete visible spectrum), is extremely interesting for the light it throws upon the subject in hand. The table of results explains itself at once to any student of physics. The lime-light used, it may be added, was a very powerful one; the sunshine, however, was not very bright or very constant, owing to the drifting of clouds. The latter fact explains the apparent slight anomaly in the results of the solar radiation given in Series II. and III. The observations were made however with the solar radiation (as estimated by a Croo'ses' Radiometer) approximately the same for them all.

Tubie to show the Sifting Power of Ice and Snow upon Radiation of different Phases of Quality

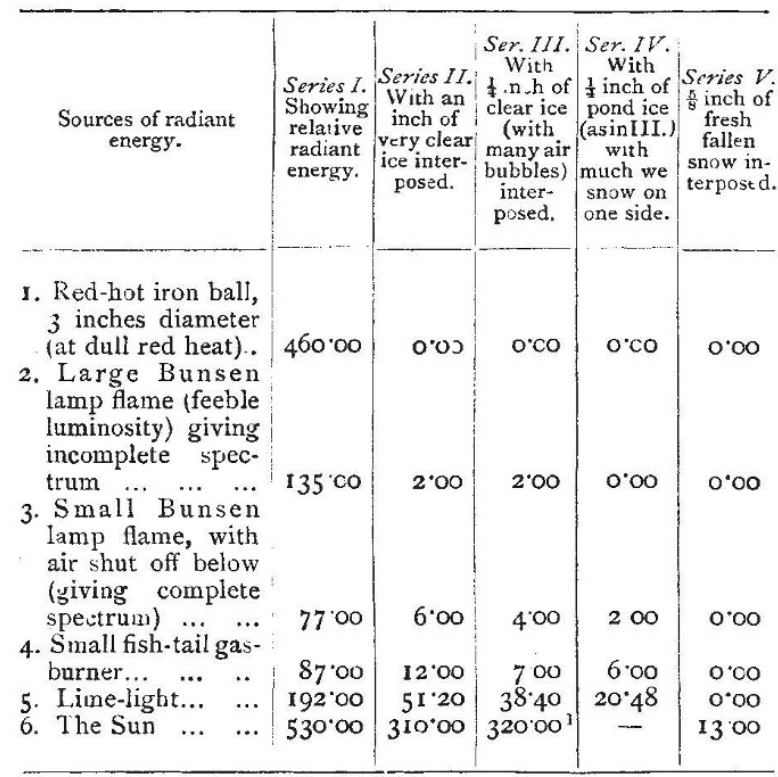

The numbers in each series in the foregoing table do not give very simple relations among themselves, and each number must be regarded as only a near approximation to the exact truth. Still, when all those slight inaccuracies which ari e from "errors of experiment " are allowed for, the general meaning and bearing of the facts remain, namely, that though heat ( $q u \hat{a}$ heat capable as it is of melting ice) cannot enter ice, yet luminous energy, which is readily absorbed and transformed into heat by opaque

${ }^{1}$ In this case a $\frac{1}{4}$-inch plate of clear ice was used. and semi-opaque bodies, can enter and pass through the ice, until it meets with a non-transparent body. Substituting for our thermopile in the experiment, stones, dirt, organic germs, \&c., within the glacier, we at once perceive how the luminous radiant energy of the sun can (by being transformed into dark heat) play its part in producing the movement of glaciers.

Further, this will be found, I believe, the only satisfactory explanation yet given of the remarkable facts ( 1 ) that glaciers move faster (in the Alps about twice as fast) during the summer than during the winter; (2) that the motion during the day is greater than during the night. This fact most people who have written on glaciers have found it difficult to explain, for when the "Regelation Theory" is fully accepted, and all that follows from it is recogmised, and when due allowance is made for internal friction, we still must seek for a cause, independent of both of these, to account for the variations in the movements of glaciers, day and night, summer and winter. This cause has now, I think, no longer to be sought for.

The glacier may be compared to a large greenhouse; as luminous energy enters freely through the glass in the one case, so it enters freely through the transparent ice in the other ; in both cases, heat available for work is produced by its transformation.

In the glacier this work is expended in diminishing the cohesion of the molecules of those parts of the ice which are in contact with the bodies which absorb the luminous energy. The beautiful silvery blue light of an ice-cavern seems to show that a part of a beam of luminous radiation is absorbed by clear ice.

The Series IV. and V. of the table illustrate the effect of $(a)$ the more or less granular condition of the ice in many parts of a glacier, $(b)$ the snow with which the glaciers are covered during the winter. The diffusive action of the latter upon luminous energy is seen by reference to Series V. to be very great; hence the necessity for the use of coloured spectacles on the higher glacier regions.

A. IRVING

\section{DEDUCTIVE BIOLOGY}

$\mathrm{T}$ has probably occurred to a good many readers of NATUke that it would be well if some one were to utter a word of warning as to the mischief which may be done, and especially to students, by the present fashion of explaining all kinds of complicated morphological phenomena in a more or less purely deductive fashion. It is no doubt pleasant, even fascinating, to sit down at one's desk and, having formulated a few fundamental assumptions, to spin out from these explanations of what we see in the world about us. But I think when done it should be understood that the result is merely a literary performance, and though, viewed in that aspect, one may admire the skill and neatness with which it is accomplished, I nevertheless venture to think that the whole proceeding is harmful.

Now, as I shall attempt to illustrate my position by reference to papers which have appeared in NATURE in particular, I may as well say at once that I have no personal or merely controversial object in writing these lines. But though it is now no part of the business of my life to take part in teaching, I have had some experience of it, and a great deal too much of testing its results by the process of examination. I have derived then a tolerably definite idea-as I believe-of the difficulties that beset the imparting of scientific instruction, and a decided conviction as to what sort of discipline is wholesome, and what is mischievous.

Of course I do not deny-far from it-the inspiriting influence which large generalisations impart to teaching. But then I think the intellectual enjoyment of them must be earned. The first thing to do is to put before the student the facts, and then, when these are conscientiously 